\title{
Saúde, direito à saúde e justiça sanitária
}

Health Care, the Right to Health and Health Justice

Santé, droit à la santé et justice sanitaire

João Arriscado Nunes

\section{CpenEdition}

\section{Journals}

Edição electrónica

URL: https://journals.openedition.org/rccs/1588

DOI: $10.4000 /$ rccs.1588

ISSN: 2182-7435

\section{Editora}

Centro de Estudos Sociais da Universidade de Coimbra

\section{Edição impressa}

Data de publição: 1 dezembro 2009

Paginação: 143-169

ISSN: 0254-1106

\section{Refêrencia eletrónica}

João Arriscado Nunes, «Saúde, direito à saúde e justiça sanitária», Revista Crítica de Ciências Sociais [Online], 87 | 2009, publicado a 15 outubro 2012, consultado a 21 setembro 2021. URL: http:// journals.openedition.org/rccs/1588; DOI: https://doi.org/10.4000/rccs.1588 


\section{JOÃO ARRISCADO NUNES}

\section{Saúde, direito à saúde e justiça sanitária}

Propõe-se uma abordagem preliminar dos processos heterogéneos e contingentes através dos quais se definem e constituem mutuamente a saúde e o direito à saúde. São apresentadas e discutidas duas manifestações recentes dessa dinâmica. A primeira situa-se na linha das transformações associadas às orientações de inspiração neoliberal no campo da saúde, apontando para a passagem da saúde como direito à saúde como imperativo, centrado na responsabilização individual e na centralidade da vigilância e da prevenção. A segunda, designada justiça sanitária, é exemplificada através de situações em que cidadãos, através da acção colectiva e mobilizando os vocabulários dos direitos e da justiça, procuram o reconhecimento como portadores de uma doença, os direitos associados a essa condição e a acção pública sobre situações que afectam a sua saúde.

Palavras-chave: biopoder; biossocialidade; direito à saúde; política sanitária; regulamentação da saúde pública; saúde pública.

\section{A saúde como um direito?}

O que significa falar da saúde como um direito? E quais as formas de acção cidadã que permitem realizar esse direito? Uma possível resposta à primeira pergunta remete-nos para o corpo do que hoje se designa por direito da saúde, as normas de direito, legislação ou jurisprudência que tratam da organização do sistema de saúde e dos serviços de saúde, do acesso a cuidados de saúde e dos direitos dos utentes de serviços de saúde, das relações entre profissionais de saúde e doentes, das condições de exercício da medicina e da realização de actos médicos, da regulação de medicamentos e técnicas médicas ou da protecção dos sujeitos humanos na investigação clínica. Mas falar da saúde como direito implica algo que está para além do domínio estrito do direito e que nos conduz a um terreno distinto, marcado por controvérsias, lutas e derivas que não passam (apenas) pelo domínio do direito da saúde: o da consagração da saúde como um direito fundamental ou um dos direitos humanos, referido no artigo $25^{\circ}$ da Declaração Universal dos Direitos Humanos.

Que a saúde possa ser considerada como um direito fundamental e consagrada na lei fundamental de um país - como acontece em Portugal - está 
longe de ser pacífico, como demonstra o caso dos Estados Unidos. Mas isso não impede que, por todo o mundo, cidadãos e comunidades reivindiquem e se batam por direitos que, mesmo quando não aparecem como parte de uma concepção ampla e coerente da saúde como direito, constituem formas de realização deste. Os próprios Estados Unidos, aliás, são um dos principais palcos da multiplicação de formas de participação pública e de organização e mobilização colectiva que tomam a saúde, o acesso a cuidados de saúde, a protecção das pessoas afectadas por problemas de saúde e o direito a viver num ambiente saudável como seu objecto.

Assumir que a saúde é um direito fundamental, porém, implica considerar as transformações por que têm passado, durante as últimas décadas, as concepções do que é a saúde e, em particular, a ampliação do conceito de saúde. Essas transformações, por sua vez, não podem ser dissociadas das mudanças nos saberes sobre a saúde e nas práticas científicas e profissionais neste campo, nem da emergência de uma diversidade de formas de governar a vida (biopoder), de reconfigurar relações sociais a partir de afinidades ou partilhas de características associadas à biologia (biossocialidade) e da constituição da "vida em si mesma" como fonte de valor e de acumulação de capital.

A diversidade de situações em que se procura afirmar e realizar a saúde como um direito fundamental não pode ser abordada de forma adequada sem considerar a relação de constituição mútua entre concepções do direito à saúde e concepções de saúde. De facto, a saúde e o direito à saúde, enquanto complexos de conhecimentos, de instituições, de práticas, de actores, de situações, são co-produzidos ou constituem-se mutuamente através de processos de construção heterogénea (Jasanoff, 2004; Taylor, 2005). O que está em jogo quando se fala de direito à saúde é tanto a luta pela definição do que conta como saúde, como daquilo que conta como direito à saúde.

Neste artigo, propõe-se uma abordagem preliminar dos processos heterogéneos e contingentes através dos quais se definem e constituem mutuamente a saúde e o direito à saúde. Optou-se, aqui, por considerar duas manifestações recentes dessa dinâmica, que apontam para direcções contrárias, e que permitem uma primeira reflexão sobre a constituição mútua de concepções "ampliadas" da saúde e da saúde como direito. A primeira situa-se na linha das transformações associadas às orientações de inspiração neoliberal no campo da saúde, apontando para a passagem da saúde como direito à saúde como imperativo, centrado na responsabilização individual do "sujeito somático" (Novas e Rose, 2000) e na sua vinculação a um complexo médico-industrial e à centralidade da vigilância e da prevenção. A segunda, que é aqui designada por justiça sanitária, é exemplificada através de situações em que cidadãos procuram ser reconhecidos como portadores de uma doença 
que lhes deveria garantir o acesso a um conjunto de direitos (consagrados pela ordem constitucional ou em normas legais específicas), ou reivindicam acção sobre situações que afectam a sua saúde. Essa luta passa, em alguns casos, pela iniciativa individual (procurando mobilizar, conforme os casos, redes de relações dentro e fora de instituições e organizações) e, em outros casos, pela organização colectiva. Estas situações têm em comum a reivindicação do reconhecimento da doença e da condição de doente ou de pessoa afectada por um distúrbio ou problema como condição de acesso a cuidados de saúde. O que confere especial interesse a estes casos é a forma como, em contraste com a primeira orientação, os seus protagonistas recorrem aos vocabulários dos direitos e da justiça para fundar as suas exigências e as suas lutas e para construir identidades colectivas. A designação de justiça sanitária é aqui utilizada num sentido análogo ao de justiça ambiental, mas serão abordadas apenas - e de forma necessariamente concisa - as formas situadas da sua invocação e "realização", enquanto respostas a situações de reconhecimento de injustiças que podem ser enfrentadas, reduzidas ou corrigidas através de modos adequados de acção, associados ou não a uma crítica mais ampla da ordem social ou a projectos de construção de uma ordem social mais justa. ${ }^{1}$

A orientação para a saúde como imperativo assenta a sua legitimidade na mobilização das ciências da vida "pós-genómicas" e da epidemiologia convencional; a orientação para a justiça sanitária apoia-se num conjunto diverso de formas de conhecimento, mas que têm em comum a consideração de uma diversidade de condições biológicas, sociais e ambientais em configurações que dão expressão a concepções "ampliadas” de saúde, mesmo quando o seu propósito é conseguir um diagnóstico clínico e uma “objectivação" biológica da doença. ${ }^{2}$ Finalmente, é importante sublinhar

\footnotetext{
${ }^{1}$ A concepção de justiça aqui avançada aproxima-se, em alguns aspectos, da que propõe Amartya Sen (2009); mas as principais fontes de inspiração para ela são, por um lado, a riquíssima experiência dos movimentos e iniciativas no campo da justiça ambiental e, em particular, da luta pela saúde ambiental (Brown, 2007, Corburn, 2005, Porto, 2007, Matias, 2009), e, por outro, a noção de solidariedade pragmática (Farmer, 2005), que designa as formas de realização parcial e situada da solidariedade, seja em situações da vida quotidiana, seja em situações de excepção, como catástrofes ou epidemias, mas apontando para uma ordem social mais justa. Este tema pede uma discussão mais aprofundada, mas que terá de ser deixada para outro lugar.

2 As situações caracterizadas pelo confronto entre concepções do sofrimento e terapias associadas a epistemologias/ontologias distintas apresentam particularidades que exigem uma abordagem específica. Mas veja-se Meneses (2004) sobre as medicinas tradicionais e Nathan (2001, 2007), Nathan e Stengers (1995) e Fassin (2004) sobre o projecto da etnopsiquiatria, que aparece como um caso especialmente interessante de prática terapêutica apoiada no respeito de ontologias e epistemologias "outras", como condição para um relacionamento não-desqualificante ou violento e para a constituição do que Santos designa por ecologias de saberes (Santos, 2009). Veja-se ainda, para uma discussão mais ampla do tema da diversidade de epistemologias/ontologias, Escobar (2007); Santos (2004); Santos e Meneses (2009); Santos (2009); Nunes (2009); Blaser (2009). Mantendo-se
} 
que ambas as dinâmicas dão corpo a formas distintas de biopoder (Rabinow e Rose, 2003) e de biossocialidade (Rabinow, 1996; Gibbon e Novas, 2008), formas de poder que tomam a vida e os seres vivos por seus objectos e configurações de relações sociais baseadas na partilha de certas características biológicas com implicações para a saúde.

\section{O “imperativo da saúde" e os seus críticos}

Nos últimos anos têm surgido estudos, ensaios, comentários e intervenções políticas que interrogam a evolução recente da saúde e da medicina - principalmente, ainda que não exclusivamente, nas sociedades do hemisfério Norte - enquanto parte da arquitectura de novas formas de vigilância, de enquadramento e de individualização dos cidadãos, especialmente através do tema reiterado da responsabilização individual. A saúde é descrita, assim, como um "imperativo" (Lupton, 1995), e o "princípio de prevenção" e a sua relação com a "mise en risque" do mundo como um novo quadro normativo que define o cidadão responsável, que adopta condutas saudáveis ou minimizadoras do risco, envolvendo a sua vinculação a um novo complexo médico-industrial (Peretti-Watel e Moatti, 2009). Esse complexo integra em novas e densas relações a indústria farmacêutica e da biotecnologia, a indústria de equipamentos médicos, a profissão médica e outras profissões ligadas à saúde, investigadores e instituições como as universidades e os centros de investigação, as novas organizações privadas que prestam cuidados de saúde, as seguradoras, organizações não-governamentais trabalhando neste domínio e os Estados e os sistemas públicos de saúde "reformados" segundo as receitas neoliberais. A saúde transformou-se, assim, num bem valioso, transaccionado no mercado, e que promete uma vida mais longa e com mais qualidade a quem estiver disposto a vincular a sua vida ao complexo médico-industrial, tornando-se um "doente em suspenso", responsável pela procura das suas susceptibilidades a problemas de saúde e à renúncia e à denúncia de comportamentos de risco. O bomo medicus, pautando a sua vida pelos imperativos da saúde, aparece como a expressão dessa nova concepção da saúde como responsabilidade individual, viabilizada pela crescente dependência em relação ao complexo médico-industrial (Peretti-Watel e Moatti, 2009). Alguns autores chegam mesmo a falar em "saúde persecutória" (Castiel e Álvarez-Dardet Diaz, 2007). ${ }^{3}$

no campo da biomedicina, Mol (2002) tem explorado, numa linha que converge em muitos pontos com as orientações mencionadas, o que designa por política ontológica, referindo-se às diferentes maneiras de "realizar" doenças e corpos através de práticas médicas (veja-se também as contribuições incluídas em Berg e Mol, 1998).

${ }^{3}$ Noutro contexto - o de uma epidemia de cólera na Venezuela nos anos 90 -, Briggs e Mantini-Briggs (2003) falam de "cidadania sanitária" para se referir à deferência dos cidadãos para com as orientações de especialistas e instituições públicas em relação à saúde. 
A denúncia da crença na "saúde perfeita" e na capacidade de os problemas de saúde, dos limites à longevidade e da qualidade de vida poderem ser resolvidos pela medicalização da sociedade não é, certamente, nova. Nem a transformação em problemas a resolver pela medicina dos problemas associados à ordem social, económica e política, a relações de poder desiguais, às desigualdades de rendimento, à injustiça ambiental e cognitiva, à discriminação baseada no sexo, na orientação sexual, na raça, na etnia ou na religião. Já desde a década de 1970, pelo menos, autores como Ivan Illich (1978), Lucien Sfez (1995) ou Thomas Szasz (2007) se pronunciaram sobre o que consideravam ser as ilusões e os perigos da medicalização da sociedade. Mas o que caracteriza as novas tomadas de posição é a sua chamada de atenção para o modo como a crença nas virtudes da medicalização está a par da promoção da responsabilidade individual pela saúde, própria e dos outros, e especialmente das gerações seguintes. Um fenómeno análogo parece verificar-se no domínio da defesa do ambiente, também ela marcada, de maneira crescente, por apelos à responsabilidade individual pelas práticas de protecção do ambiente e à ideia de que os problemas ambientais poderão, senão ser resolvidos, pelo menos ser mitigados pela acção responsável de cada um de nós enquanto consumidor - e das empresas, encorajadas a adoptar tecnologias e formas de organização da produção e da distribuição mais "amigas do ambiente". O corolário desta visão - sem negar a relevância das acções e iniciativas individuais é o recuo da ideia de que a resposta aos problemas ambientais exige, acima de tudo, transformações radicais nas formas de organização da economia e da sociedade e da ordem política. Andrew Szasz (2008) fala, a este respeito, de "quarentena invertida": em lugar de se bater por políticas públicas que defendam o ambiente, cada pessoa procura proteger-se a si própria tornando-se consumidora de água engarrafada, protectores solares ou produtos "verdes".

Configura-se, assim, uma nova forma de biopoder - um conjunto de discursos, com pretensão de verdade, sobre a vida e a saúde; entidades com autoridade para os pronunciar; estratégias de intervenção na existência colectiva em nome da defesa da vida e da saúde; e novos modos de constituição de sujeitos (Rabinow e Rose, 2003). O indivíduo é induzido a comportar-se cada vez mais como "empreendedor de si mesmo e da sua vida" (Foucault, 2004), da sua saúde e do "seu” ambiente. Como sugeria, em 1977, J. H. Knowles, cardiologista e presidente da Fundação Rockefeller, a noção de direito à saúde deveria ser substituída pela "obrigação moral", uma "espécie de dever público" que cada um teria de preservar a sua saúde (Knowles, apud Peretti-Watel e Moatti, 2009: 23). 
A disciplina-base da saúde pública, a epidemiologia, contribui, hoje, pelo menos nas versões convencionais associadas ao "modelo epidemiológico dominante" (Brown, 2007) - para reforçar esta orientação, e fornece os instrumentos para a legitimar cientificamente, como a identificação de "factores de risco". Como lembram Peretti-Watel e Moatti (2009: 24), nada é intrinsecamente um risco; a transformação de algo em risco tem a ver com a procura do controlo do corpo e do seu ambiente, ou, por outras palavras, com a domesticação da incerteza. Mas à medida que se expande essa noção a novos problemas e a terrenos e objectos novos e heterogéneos, começa a ser clara a inadequação dos instrumentos que são habitualmente mobilizados para a avaliação de risco e para a produção da informação a esta necessária. Ao centrar-se nos factores de risco, a epidemiologia convencional faz proliferar o número desses factores, mas sem que tal signifique que se compreenda como eles afectam o fenómeno com que se procura lidar (os riscos diferenciais de doença cardiovascular ou de certos tipos de cancro em subpopulações ou grupos específicos, por exemplo). Não será de admirar, por isso, que algumas políticas dirigidas a riscos específicos sejam políticas que se baseiam numa abordagem que tem em conta a situação particular em que se intervém e a complexidade das relações que nelas estão em jogo - como acontece com as políticas de redução de riscos no domínio da toxicodependência (Coppel, 2002).

A figura do bomo medicus - ou, como lhe chamaram Novas e Rose (2000), do indivíduo ou sujeito somático - corresponde a uma forma de subjectivação que pressupõe, para a sua constituição, a existência de dispositivos e de vinculações que serão analisados na secção seguinte. O homo medicus encontra-se, por definição e de maneira permanente, numa situação "infrapatológica", ou, quando apresenta certas predisposições ou factores de risco, na condição de "doente saudável", assintomático ou pré-sintomático. Os "comportamentos de risco" colocam-no na mesma situação.

Que dispositivos permitem promover estas formas de subjectivação? Em primeiro lugar, a subordinação dos cidadãos à autoridade dos especialistas, legitimada pelo saber biomédico. Mas para o mesmo resultado concorre também, como mostraram Pignarre (2001) e Lakoff (2008) a propósito das doenças do foro psiquiátrico, a produção de medicamentos e de tecnologias biomédicas para os quais são, depois, procurados os doentes e as doenças "apropriados".

\footnotetext{
${ }^{4}$ Para uma excelente discussão destes problemas e de concepções alternativas do saber epidemiológico e da sua construção, veja-se Almeida Filho (2000).
} 
O "culto da saúde", que vai de par com a ambição de erradicar os riscos, e o princípio de prevenção, que ajuda a multiplicar os riscos sobre os quais se deve agir, promove entre os utentes/consumidores disposições como a responsabilidade e o "empreendedorismo de si mesmo", assim como a deferência aos peritos (Peretti-Watel e Moatti 2009: 30), alimentando modalidades de "empreendedorismo moral", que, como sublinham os mesmos autores, geram consequências significativas e problemáticas (2009: 31). A estigmatização associada à condenação de "comportamentos de risco" tem efeitos que não estão inteiramente esclarecidos para a saúde pública, mas tende a criar problemas (mesmo que localizados e temporários) aos seus "alvos". Pode também levar ao reforço de uma moral conservadora, em nome da saúde e da segurança, que por sua vez contribui para agravar o problema que se propunha combater (por exemplo, a promoção da abstinência ou da fidelidade em lugar do sexo seguro, ou o "just say no" em relação às drogas). A insistência na responsabilização individual contrasta com os limites e as dificuldades da intervenção dos Estados na regulação das formas de contaminação e de poluição a que estão sujeitos os cidadãos e comunidades. As fontes dessas agressões ao ambiente e à saúde encontram-se, frequentemente, em actividades industriais ou agrícolas cujo peso económico e político é suficiente para contrabalançar iniciativas de protecção da saúde pública susceptíveis de as afectar. E é importante lembrar a forma como o Estado beneficia, nomeadamente por via fiscal, de algumas actividades (como a da indústria tabaqueira ou de bebidas alcoólicas) que, ao mesmo tempo, denuncia como estando na origem de problemas graves de saúde pública, com custos humanos, materiais e ambientais consideráveis.

Neste contexto pode-se compreender como iniciativas centradas na promoção da saúde através da ênfase na prevenção primária se tornam vulneráveis a "capturas" e derivas associadas à ênfase na responsabilização individual dos cidadãos.

\section{A biomedicalização da saúde e o "sujeito somático"}

O processo descrito na secção anterior está estreitamente vinculado a um conjunto de transformações que, ao longo das últimas três décadas, têm vindo a marcar, ainda que de forma desigual e com ritmos diferenciados, as concepções da saúde, os saberes, as políticas e as instituições do sector da saúde em todo o mundo. Podemos caracterizar essas transformações a partir de três aspectos principais.

\footnotetext{
${ }^{5}$ Sobre as diferentes orientações no campo da promoção de saúde e os debates em curso sobre o tema, veja-se Czeresnia e Freitas (2003) e Carvalho (2005).
} 
O primeiro é a biomedicalização da saúde, isto é, a crescente importância e centralidade dos saberes das ciências da vida na definição e gestão da saúde, com a concomitante promoção de uma monocultura dos saberes e práticas da saúde, associada principalmente à molecularização e geneticização da medicina (Clarke et al., 2003; Rose, 2007). A vigilância, a monitorização, a avaliação e a gestão de riscos passam a ocupar um lugar de crescente importância, precisamente, apoiadas nas tecnologias de visualização, de rastreio, de análise e de uma "visão molecular da vida", que a considera como potencialmente maleável, através da intervenção humana, e que está associada a uma divisão do trabalho, diferenciando e fragmentando os "objectos" da medicina. As práticas no campo da saúde passam também a ser cada vez mais configuradas pelas exigências de uma nova economia política da saúde, sujeita aos imperativos de grandes grupos e empresas, de seguradoras e, em geral, do mundo do que hoje se designa por biocapital, e que chega aos próprios sistemas públicos de saúde. Neste quadro, cada pessoa deverá, idealmente, tornar-se vigilante de si própria, responsável pela monitorização e manutenção de seu estado de saúde, incluindo a adopção de um estilo de vida saudável, de uma dieta apropriada, da prática de exercício e da sujeição regular a rastreios e exames, dando forma a uma "subjectividade somática” (Novas e Rose, 2000). Esta nova situação caracteriza-se, em primeiro lugar, pela distância entre a capacidade de vigilância, de diagnóstico e de monitorização, por um lado, e a disponibilização de terapias eficazes, por outro; e, em segundo lugar, pela importância crescente da ideia de optimização do sujeito somático. O processo de biomedicalização vive, em boa medida, de notas promissórias, apoiadas na capacidade crescente de intervenção nos processos biológicos e na sua manipulação, mas não se sabe se e quando essas notas promissórias serão remidas, especialmente no que respeita às terapias e às intervenções de "optimização". Cada pessoa, entretanto, tenderia a assumir a condição de "doente saudável", sujeita a sofrer um problema grave no futuro, revelada, por exemplo, por um perfil genético, e que só poderia ser, eventualmente, resolvido através de mais inovações no domínio da terapia e da manipulação da vida, como a farmacogenética, os xenotransplantes, as tecnologias de produção e regeneração de órgãos ou a nova neuroquímica. A responsabilidade última por zelar pela saúde acaba, assim, por residir em cada um de nós.

À medida que estes instrumentos e meios de vigilância e monitorização vão sendo apropriados por empresas, seguradoras e instituições do Estado, a saúde torna-se, por sua vez, um pretexto para a vigilância e a discriminação. A "saúde persecutória" introduz na sociedade novas formas de classificação das pessoas, em função da sua capacidade de se conformar com o 
imperativo de ser saudável e de características que são identificáveis a partir dos novos meios de rastreio e de vigilância, distribuindo-as por grupos de risco específicos. A capacitação do doente/utente passa, cada vez mais, pela sua transformação em consumidor ou cliente de serviços de saúde e pelo acesso crescente a informação disponibilizada, por exemplo, na Internet. A biomedicalização assim entendida distingue-se, pois, do "modelo biomédico" - que foi, e continua a ser, alvo de críticas por parte de diferentes correntes postulando visões "ampliadas" da saúde, como a medicina social latino-americana, as várias versões da epidemiologia crítica ou, no Brasil, a Saúde Colectiva, a que voltaremos mais adiante -, que era ainda uma prática voltada para a doença e menos dependente, na sua prática quotidiana, dos saberes e tecnologias das ciências da vida e biotecnologias. $\mathrm{Na}$ nova dinâmica, o conceito de saúde é individualizado e recentrado nos processos biológicos - e especialmente na genética - e nos comportamentos individuais, subsumidos na noção de estilo de vida, tendendo a desaparecer a referência aos determinantes sociais e ambientais da saúde. ${ }^{6}$

Um segundo aspecto é a nova economia política da saúde, com a emergência de novas formas de biocapital ligadas ao encontro entre as biotecnologias, o capital de risco e as grandes empresas farmacêuticas, e o surgimento de novos tipos de organizações que transformam os médicos e outros profissionais de saúde em accionistas ou assalariados, cada vez mais afastados da concepção tradicional da medicina liberal e da sua deontologia; é de salientar, em particular, a tendencial imposição, nas práticas de saúde e na organização do sector, de uma lógica da escolha e da "clientelização" sobre uma lógica do cuidado, do envolvimento activo e colaborativo no que podemos designar de co-produção da promoção de saúde e da atenção em saúde, ajustadas a diferentes situações e condições de vulnerabilidade (Mol, 2008). A saúde vê assim confirmada a sua conversão num conjunto de bens e serviços adquiridos num mercado ou através da organização de convenções em que o Estado passa, crescentemente, de prestador a financiador de serviços e de bens fornecidos por entidades privadas, e os doentes/utentes a clientes. O conhecimento e a própria vida - sob a forma de tecidos humanos, genes, linhas celulares, órgãos, bens de biodiversidade torna-se sujeito a apropriação privada através de patentes, protegida pelos regimes existentes de propriedade intelectual.

\footnotetext{
${ }^{6}$ Aqueles que se recusam a assumir a condição de indivíduos somáticos responsáveis pela sua própria saúde, ou de "cidadãos sanitários" tornam-se facilmente alvo de reprovação social, inclusive dos seus familiares e amigos, e de acusações de irresponsabilidade. Veja-se a notável discussão de um desses casos em Callon e Rabeharisoa (2004).
} 
O terceiro aspecto é a emergência de uma política da "vida em si mesma" (Rose, 2007), centrada na vida como fenómeno biológico, associada às crescentes capacidades, já referidas, de diagnóstico, de vigilância e de intervenção nos processos biológicos, com implicações nas formas de poder, de governo, de socialidade e de subjetivação, mas também de mobilização colectiva. Também aqui se verifica um estreitamento em relação à concepção ampla de vida, abrangendo as condições sociais e a experiência dos sujeitos, que é constitutiva das concepções "ampliadas" de saúde. Contudo, contrariamente às visões deterministas e simplificadoras que acompanham a celebração das novas tecnologias da vida, mas também às visões críticas que tendem a subscrever esse determinismo, as tecnologias são, elas próprias, instáveis, sujeitas a contestação e a reapropriação, abrindo caminho à emergência de outras formas de política da vida.

Um aspecto crucial destas transformações é a diversidade de escalas em que elas ocorrem e as interferências entre essas escalas, que levam a que a definição das políticas de saúde e das suas prioridades em cada país sejam vinculadas, de múltiplas formas, a dinâmicas regionais ou globais protagonizadas pelos governos de países centrais, pelas transnacionais do sector farmacêutico e biotecnológico, pelas organizações privadas prestadoras de serviços de saúde e pelas organizações de pesquisa médica, pelas organizações internacionais e multilaterais, como o Banco Mundial, o FMI ou a OMC, mas também pela resistência e pelo activismo de fóruns, plataformas, movimentos e iniciativas que lutam pela afirmação e realização da saúde como um direito fundamental.

\section{A saúde como direito e as concepções "ampliadas" de saúde}

A partir do reconhecimento do direito a um padrão de vida que garanta a saúde pela Declaração Universal dos Direitos Humanos $\left(\right.$ art. $^{\circ} 25^{\circ}$ ), a saúde foi consagrada como direito fundamental em diferentes constituições nacionais, incluindo a Constituição da República Portuguesa. Não é consensual, contudo, a ideia de que a saúde possa ser considerada como um direito e, mesmo nos casos em que tal ocorre, não existe acordo sobre a definição e as condições de realização do direito à saúde. A consagração da saúde como direito está, em geral, associada a duas ideias-chave: a sua universalidade - a saúde é um direito de todos os cidadãos - e a de que a saúde - conforme a conhecida definição da Organização Mundial de Saúde - não deve ser considerada simplesmente como ausência de doença, mas como um estado geral de bem-estar, cuja realização e protecção dependem de um conjunto de condições económicas, sociais e políticas que transcendem o domínio circunscrito das políticas de saúde e dos cuidados de saúde. 
O caso do Brasil aparece como um dos exemplos mais interessantes quer de constitucionalização desse direito, quer das dificuldades e tensões associadas à sua realização. Vale a pena, por isso, examiná-lo com alguma atenção. A Constituição Federal do Brasil de 1988 consagra a saúde como um "direito de todos e um dever do Estado" (art. ${ }^{\circ}$ 196), apoiado numa definição de saúde mais ampla ainda do que a proposta pela OMS. Essa definição ampla havia sido avançada pelo Movimento da Reforma Sanitária, durante as lutas pela democratização do país, e seria vertida no texto constitucional a partir de uma proposta de emenda popular apresentada por aquele movimento. ${ }^{7}$ A VIII Conferência Nacional de Saúde (1986), que constituiu um marco decisivo desse processo, definiu a saúde como:

- "o resultado das condições de alimentação, moradia, educação, renda, ambiente, trabalho, transporte, emprego, lazer, liberdade, acesso à posse da terra e acesso a serviços de saúde..., o resultado das formas de organização social da produção, que podem gerar grandes desigualdades de nível de vida”.

- uma conquista da população, definida em "um contexto histórico de uma sociedade determinada e num dado momento de seu desenvolvimento, [e que] deve ser conquistada pela população através das suas lutas quotidianas".

- um direito, que ganha forma através da garantia, pelo Estado, "de condições de vida dignas e de acesso universal e igualitário às acções e serviços de promoção, protecção e recuperação da saúde, a todos os níveis, para todos os habitantes do território nacional, conduzindo ao pleno desenvolvimento do ser humano na sua individualidade".

- esse direito é formalizado no texto constitucional, mas realiza-se, sobretudo, através de uma política de saúde "consequente e integrada nas outras políticas económicas e sociais", com os meios necessários à sua execução e garantindo o "controle do processo de formulação, gestão e avaliação das políticas sociais e económicas pela população" (Oitava Conferência Nacional de Saúde, 1986: 4).

Como notou Dina Czeresnia, porém, a ampliação da concepção de saúde para além da "ausência de doença" traz consigo um conjunto de novas interrogações:

Apesar de configurar avanço inquestionável tanto no plano teórico quanto no campo das práticas, a conceituação positiva de saúde traz novo problema. Ao se considerar saúde em seu significado pleno, está-se lidando com algo tão amplo como a própria

\footnotetext{
${ }^{7}$ Sobre o processo que levou à inscrição da saúde como direito fundamental na Constituição Federal do Brasil de 1988, veja-se Neto (2003), que é ao mesmo tempo um relato pormenorizado e uma reflexão sobre esse processo, por um dos seus principais protagonistas.
} 
noção de vida. Promover a vida em suas múltiplas dimensões envolve, por um lado, ações do âmbito global de um Estado e, por outro, a singularidade e autonomia dos sujeitos, o que não pode ser atribuído à responsabilidade de uma área de conhecimento e práticas. (Czeresnia, 2003: 46)

Discuti noutro lado (Nunes, 2008) como esta redefinição da saúde aponta, por sua vez, para a possibilidade de uma ampliação das políticas de saúde no sentido de uma política da vida distinta da que está associada à biomedicalização, que obrigaria a reconfigurações significativas das práticas políticas e das políticas públicas e da própria organização do Estado. Mas uma definição ampliada da saúde pode assumir significados diferentes e materializar-se em práticas, formas de organização, formas de poder e de socialidade distintas. Uma primeira possibilidade foi discutida nas secções anteriores. A ampliação do conceito de saúde dá-se, neste caso, através do continuado "puxar" das intervenções biomédicas numa direcção a montante dos sintomas e das patologias diagnosticáveis, associado à ênfase na responsabilidade individual na adopção de estilos de vida saudáveis e de submissão a uma vigilância médica regular ou continuada e na identificação de susceptibilidades e riscos.

A segunda possibilidade aponta para a crescente importância de duas orientações que, com frequência, aparecem associadas e se potenciam mutuamente. A primeira diz respeito a políticas públicas dirigidas a situações e processos susceptíveis de afectar a saúde e o bem-estar de cidadãos, comunidades ou grupos específicos e à promoção de um ambiente saudável e de condições sociais e económicas dignas para todos. A segunda refere-se às acções e iniciativas de cidadãos, comunidades, grupos e movimentos (incluindo movimentos de profissionais e especialistas em saúde), reivindicando o reconhecimento de problemas ou distúrbios que afectam a sua saúde e bem-estar e/ou intervenções públicas que permitam prevenir esses problemas ou distúrbios. Num artigo publicado em 2006, com o sugestivo título "Illnesses You Have to Fight to Get" ("Doenças que se tem de lutar para ter”), Joseph Dumit chamava a atenção para as controvérsias e mobilizações colectivas em torno de doenças emergentes ou com características consideradas incertas pelo saber biomédico e epidemiológico. De facto, a expressão usada por Dumit pode ser alargada a um conjunto de situações para além daquelas a que ele se refere no seu artigo, para abranger, em geral, as lutas por aquilo que designarei, em termos gerais, de justiça sanitária. Não se trata, aqui, apenas de lutas que têm como foco o acesso a serviços de saúde, hoje muitas vezes incluídas nos movimentos de consumidores ou de utentes de serviços públicos. Estamos, antes, perante um conjunto de 
situações em que a realização do direito à saúde passa pelo reconhecimento da existência de doenças ou da existência de pessoas ou grupos na sociedade afectados por certas doenças, geralmente causadas por exposições ambientais ou condições sociais ou laborais, cuja existência pode ser contestada ou negada por profissionais, investigadores e instituições de saúde ou de protecção social, e pelo apoio (ou ausência de apoio) do Estado e compromisso público com a intervenção sobre a doença. ${ }^{8}$ Destas situações emergem diferentes formas de acção e de mobilização colectiva, cujos objectivos podem incluir: acesso a serviços e cuidados; inclusão em categorias que têm acesso a cuidados médicos de um certo tipo; maior investimento na investigação, no desenvolvimento de terapias e na assistência a pessoas que sofrem de doenças negligenciadas ou órfãs; reconhecimento de certos problemas ou perturbações como doenças e daqueles que são afectados por essas doenças como tendo direito a cuidados de saúde; reconhecimento de relações causais entre exposições a substâncias e agentes contaminantes e determinadas doenças ou distúrbios; desmedicalização de certos problemas ou condições; reconhecimento de formas de sofrimento e de terapias a estas dirigidas, que se associam a epistemologias/ontologias distintas da epistemologia/ontologia naturalista em que se apoia a biomedicina. Muitas das acções no campo da justiça ambiental incidem, igualmente, sobre problemas que afectam a saúde e sobre a exigência do seu reconhecimento pelo Estado, pelas autoridades de saúde e pelos especialistas e profissionais.

Estas situações apontam para uma tensão importante nos processos políticos apoiados em concepções "ampliadas" de saúde. Se a saúde é definida como algo mais amplo do que a ausência de doença, e os problemas que afectam a saúde como algo mais do que a existência de doença, as acções referidas acima podem aparecer como paradoxais. Essas concepções ampliadas de saúde constituem, por um lado, um recurso mobilizável para a luta pela saúde como um direito. Mas as formas que assume essa luta - especialmente aquelas que resultam em avanços efectivos no plano das políticas públicas e da organização da sociedade -, parecem estar vinculadas a uma luta pelo "direito à doença", ou seja, pelo reconhecimento da existência de doenças ou da condição de pessoa, grupo ou comunidade afectados por essas doenças. Por outras palavras, e recorrendo a um vocabulário

\footnotetext{
${ }_{8}^{8}$ Como nota Epstein numa resenha recente dos estudos sobre grupos de doentes e movimentos sociais na saúde, entre as questões que estão no centro da investigação sobre o tema encontra-se o processo colectivo de formação de "disease constituencies" e de "illness identities", através dos quais os doentes organizados se transformam em actores políticos colectivos (Epstein, 2008: 499). Para uma abordagem mais ampla da constituição, pela acção pública, mobilizações de colectivos "afectados" ou "órfãos" nos domínios da saúde e do ambiente, entre outros, veja-se Callon et al. (2001).
} 
consagrado nas ciências sociais, concepções ampliadas de saúde são mobilizadas para reivindicar, precisamente, a medicalização de certas perturbações e de certos problemas, através do seu reconhecimento como doenças, com causas e etiologias por vezes desconhecidas ou complexas. É através do processo de identificação dessas causas e etiologias que toma forma, em muitos casos, a luta pela saúde como direito.

\section{Justiça sanitária e "direito à doença"}

Como se entende que, apesar da generalização de abordagens preventivas e do princípio da promoção da saúde, a realização do direito à saúde tenha de passar por reivindicações de reconhecimento de que se é afectado por uma doença, e pela exigência de resposta a essa condição? As situações que serão discutidas a seguir parecem indicar que o caminho para o reconhecimento da saúde como direito passa por uma definição da condição de doente ou de pessoa afectada por um distúrbio, em termos que sejam reconhecidos como legítimos pelo saber biomédico e pelos seus porta-vozes e pelas instituições responsáveis pelas políticas públicas de saúde. Esta exigência afecta especialmente os que são mais vulneráveis, com acesso a menos recursos materiais, que se encontram em condições precárias de emprego ou de habitação, que são obrigados a habitar em zonas insalubres, contaminadas ou expostas a contaminações, que são vítimas de formas diversas de violência estrutural e que vêem a sua voz desautorizada ou deslegitimada pelo discurso de responsáveis políticos, instituições, peritos, empresas e meios de comunicação social. Ao contrário dos discursos e movimentos que criticam a medicalização, os cidadãos que se mobilizam para ver reconhecida a sua condição de doentes ou de pessoas, grupos ou comunidades afectados por um problema de saúde procuram definir a sua condição em termos que a "medicalizam", que a tornam identificável como uma condição exigindo acesso a cuidados médicos e a direitos associados ao reconhecimento dessa condição. A acção de especialistas e instituições sobre essa condição, a definição de intervenções médicas e de políticas públicas a ela dirigidas passam a ser a premissa de uma acção positiva para promover a saúde e assim realizar o direito à saúde para além da intervenção sobre a doença.

Mas esta medicalização não significa um simples alinhamento com o que os críticos da medicalização e os proponentes de algumas definições "ampliadas" da saúde designam por "modelo biomédico". O que se nota, antes, nos tipos de situações que serão comentadas a seguir é a apropriação, revisão, transformação e reconfiguração dos saberes sobre a doença e a saúde, de modos distintos, mas que apontam para uma ampliação, de facto, dos modos de produzir conhecimento sobre a doença, de a definir e de apontar 
os caminhos possíveis de resposta a ela. Alguns autores designam este processo por (bio)medicalização incompleta ou parcial (Dumit, 2006, Klawiter, 2002). Deparamos, assim, com o aparente paradoxo de as concepções "ampliadas" de saúde tomarem forma através de um processo que se centra, precisamente, na identificação e definição de doenças, das suas causas, da sua etiologia e dos modos de actuar sobre esta e sobre os seus efeitos, mas que, ao mesmo tempo, exige o recurso a modelos explicativos e a modos de conhecimento que ampliam ou transformam os saberes biomédicos. Por outras palavras, realizar o direito à saúde pode passar por reconfigurar os saberes da biomedicina e da epidemiologia sobre as doenças. ${ }^{9}$ A ampliação e consolidação do conhecimento sobre as manifestações da doença, a sua etiologia ou as suas causas leva à proposta de quadros analíticos em que se definem mutuamente o domínio ou processo que se costuma designar por biológico, social, político, cultural, económico ou ambiental. A partir desses quadros, torna-se possível pensar de maneira positiva e pragmática (e não apenas declarativa) uma noção ampliada de saúde e de políticas de saúde capaz de assumir, de facto, as implicações de tratar saúde e doença como um processo, o processo de saúde-doença, caro aos sanitaristas latino-americanos. A ênfase na susceptibilidade individual dá lugar à preocupação com a vulnerabilidade - populacional, institucional, associada a certos contextos -, e o risco é reconfigurado em termos ecossociais, no quadro de uma ecologia política da saúde (Porto, 2007).

\section{O reconhecimento da doença, da invalidez ou da deficiência}

É comum o recurso aos serviços de saúde e a profissionais de saúde para o reconhecimento e certificação da condição de doente, para efeitos, por exemplo, de baixa médica no trabalho ou na escola -, uma condição que poderá ser provisória, com a cura ou recuperação do doente, ou que poderá resultar num diagnóstico de doença crónica ou de incapacidade, parcial ou total. Mas são também frequentes as situações de procura do reconhecimento da condição de invalidez ou de perda de capacidade e de autonomia associada a doença, acidente, ferimentos ou lesões resultantes da participação em guerras ou operações militares. A exigência de reconhecimento da deficiência, congénita ou adquirida, é uma das manifestações mais frequentes de uma forma de acção, individual ou colectiva, que visa o acesso a direitos específicos, distintos daqueles de que usufruem cidadãos e cidadãs que não são afectados pelos mesmos problemas. Em certos contextos, esta pode ser uma estratégia de sobrevivência, especialmente quando estão

\footnotetext{
${ }^{9}$ Sobre o projecto da Saúde Colectiva, veja-se Campos et al. (2007) e Nunes (2008).
} 
em curso processos de transformação social que promovem a precarização das condições de trabalho e de vida e as desigualdades, como tem vindo a suceder, especialmente desde a década de 80 , com a expansão do neoliberalismo em diferentes regiões do mundo. ${ }^{10}$

A avaliação do dano e da deficiência, que é ela própria um processo de co-produção de definições científico-técnicas, jurídicas e políticas, torna-se, nestes casos, um ponto de passagem obrigatório (Latour, 1987) do processo de reconhecimento da condição de inválido ou de deficiente. O postulante a essa condição terá de passar por um conjunto de avaliações que põem à prova a relevância e a legitimidade da sua reivindicação, implicando-o numa malha de relações com instituições do Estado, peritos e, por vezes, organizações ou associações que apoiam essa reivindicação.

Os homens e mulheres que se encontram neste tipo de situações são impelidos/as a tornar-se "praticantes" competentes de doenças reconhecidas para que possam ser reconhecido/as como doentes e aceder, assim, aos direitos associados a essa condição (Petryna, 2002). A aquisição dessa competência transforma a experiência da doença, as linguagens em que esta pode ser dita e partilhada e o próprio trabalho da pessoa doente sobre si própria enquanto sujeito (Petryna, 2002: 152-53). Uma forma de descrever este processo, como lembra Petryna, é através da noção, comum na antropologia e sociologia médicas, da passagem do "mal" como "illness", como experiência subjectiva da doença e do sofrimento, ao "mal" como patologia caracterizada pela identificação precisa de sintomas através da mobilização dos saberes biomédicos ("disease"). Essa passagem não implica apenas a familiarização com o vocabulário, os conceitos e os procedimentos da biomedicina, mas também uma aprendizagem que abranja o funcionamento das instituições, a cultura profissional dos profissionais de saúde e dos funcionários dos serviços e a forma de lidar com eles, assim como a capacidade de "encenar" de maneira adequada, em espaços clínicos e administrativos, a condição de pessoa afectada pelo(s) problema(s) de saúde em causa e de mobilizar as relações necessárias para aceder a esses espaços e para obter os diagnósticos e declarações necessários ao reconhecimento dessa condição

\footnotetext{
${ }^{10}$ A participação crescente em ensaios clínicos, em regiões do mundo com perfis epidemiológicos próximos dos da Europa Ocidental, da América do Norte e do Japão, mas com um consumo substancialmente inferior de medicamentos, que tornam as suas populações especialmente apetecidas pela indústria farmacêutica ou pelas organizações que desenham e realizam ensaios clínicos para estas - como a Europa de Leste ou partes da América Latina e da Ásia -, constitui outra forma de aceder, pelo menos durante os ensaios, a tratamentos e cuidados médicos que seriam inacessíveis de outra forma (Petryna, 2009). Para uma importante análise das formas de cidadania biomédica associadas à consideração da diversidade nos ensaios clínicos, no caso dos Estados Unidos, veja-se Epstein (2007).
} 
(Petryna, 2002). ${ }^{11}$ É importante sublinhar, contudo, que o sucesso da acção que procura o reconhecimento como portador(a) de uma doença depende do significado epidemiológico dessa doença e do tipo de população por ela afectada, do grau de cobertura mediática que a doença recebe, bem como da aceitabilidade social desta e da condição de portador(a) da doença. Uma doença que afecta populações numerosas, que ameaça propagar-se rapidamente ou que transpõe fronteiras nacionais, de território, de classe, de sexo, de raça, de etnia ou de orientação sexual poderá suscitar mais atenção e respostas mais rápidas e eficazes do que as que tendem a confinar-se a certos espaços ou grupos. Patologias estigmatizantes, como a SIDA ou, em geral, doenças venéreas, doenças associadas à pobreza ou doenças do foro psiquiátrico podem, em certos contextos, significar a estigmatização e marginalização das pessoas que são publicamente reconhecidas como sofrendo da doença. A dependência em relação a terceiros para acesso a cuidados de saúde, como acontece em muitas regiões do mundo, especialmente no Sul global e entre as populações afectadas pela pobreza e pela exclusão em muitos países do Norte, pode constituir igualmente um obstáculo ao reconhecimento do direito de acesso a cuidados médicos. Noutros casos, como os que Petryna descreve a propósito das sequelas de um desastre tecnológico ampliado como foi a explosão de Chernobyl, ver reconhecida a condição de pessoa portadora de doenças associadas ao desastre nuclear de 1986 e às suas consequências pode significar a diferença entre ter ou não ter acesso a direitos de cidadania associados à condição de vítima de dano biológico, tornando-se a gravidade do dano um factor decisivo na atribuição, por exemplo, de compensações, de prestações monetárias, de pensões ou do direito, por exemplo, a alojamento e a outras prerrogativas. O dano biológico torna-se, nestas situações, condição de acesso à posição de doente e ao que Petryna designa por cidadania biológica, com a condição de o cidadão se transformar no que ela denomina "administrador eficiente do seu sofrimento” (Petryna, 2002: 202). Não significa isto, porém, que noutros contextos de desastre ampliado o resultado seja idêntico em termos da configuração biopolítica que emerge das consequências deste. É importante ter em conta as diferenças entre os sistemas políticos e jurídicos nacionais, a organização dos sistemas de saúde e dos sistemas de investigação científica e de perícia, as garantias constitucionais e legais de protecção da saúde

\footnotetext{
${ }_{11}$ Dumit (2000: 217-18) descreve como, através de informação disponibilizada na Internet, pessoas que sofrem de doenças com estatuto e diagnóstico controverso, como a Síndrome de Fadiga Crónica, podem aprender a gerir a informação e as consultas com os seus médicos, chegando ao ponto de dar indicações sobre como devem ir vestidas para minimizar o risco de serem diagnosticadas como sofrendo de depressão.
} 
e o papel do Estado, as várias formas de desigualdade, de socialidade e de biossocialidade, os movimentos sociais, organizações e formas de mobilização colectiva, mas também a influência de forças económicas e políticas e de autoridades científicas e técnicas internacionais. ${ }^{12}$

\section{Os distúrbios "sociomédicos" controversos}

Noutras situações, o que está em causa é a própria existência de uma doença ou a definição da doença a partir das suas causas e etiologia. O rol dos distúrbios que podem ser considerados como controversos e cuja caracterização como doença é contestada por especialistas é hoje longo, e tem aumentado à medida que vão ganhando visibilidade pública os grupos e populações que apresentam sintomas que não podem ser inequivocamente associados a uma doença nem à existência de uma lesão ou dano biológico. Nos Estados Unidos, as décadas de 80 e 90 viram multiplicar-se esses distúrbios, identificados por siglas que se transformaram rapidamente em designações de campos de batalha em torno da sua definição enquanto doenças "verdadeiras" (isto é, associadas a lesões ou danos biológicas) ou da sua relegação para os domínios da doença mental ou psiquiátrica: CFS (Chronic Fatigue Syndrome), MCS ou ED (Multiple Chemical Sensitivity ou Environmental Disease), GWS (Gulf War Syndrome), AD/HD (Attention Deficit/Hyperactivity Disorder), SBS (Sick-Building Syndrome) e, embora gerando hoje menos controvérsia, PTSD (Post-Traumatic Stress Disorder), depressão ou esquizofrenia. ${ }^{13}$

Dumit (2000: 210; 2006: 578) identifica as seguintes características comuns a estes distúrbios: o seu carácter crónico; o desacordo sobre a

\footnotetext{
${ }^{12}$ No Brasil, o recurso ao Ministério Público - que tem como missão garantir o respeito pelos chamados direitos difusos, incluindo o direito à saúde e ao ambiente - é parte do reportório de procedimentos através dos quais os cidadãos procuram aceder a medicamentos e terapias. Neste caso, é necessário algum conhecimento da forma de acesso ao Ministério Público e da forma como este pode accionar os procedimentos que garantam o acesso a esses meios, nomeadamente a partir da invocação das disposições constitucionais. Esta prática, que assenta na concepção do direito à saúde como direito individual, é hoje muito frequente, e tem alimentado um importante debate sobre a judicialização da saúde e as suas implicações orçamentais, que podem afectar a equidade no acesso ao sistema de saúde e aos recursos deste. As ligações desta situação à concepção da "cidadania farmacêutica" cujo modelo é a política, definida na década de 1990, em relação à SIDA e aos que são por ela afectados, mereceria um tratamento específico e pormenorizado. Sobre este tema, veja-se o importante estudo de João Biehl (2007).

${ }^{13}$ A dor crónica apresenta uma história que se aproxima, em alguns pontos, das dos distúrbios mencionados (Baszanger, 1995). Existe uma longa bibliografia que aborda a história destes diferentes distúrbios. A título de exemplo, veja-se, para o PTSD, Young (1995); para a MCS, Kroll-Smith e Floyd (1997); para a SBS, Murphy (2006); para a GWS, Brown (2007); para a depressão, Pignarre (2001). Dado que nem todos os distúrbios têm traduções "estabilizadas" em português, optei por manter as suas designações em língua inglesa.
} 
natureza mental, psicológica ou biológica do distúrbio; a indeterminação das suas causas e etiologias indeterminadas; a tendência dos que são afectados pelos distúrbios a organizar-se ou coordenar-se na base da partilha de uma forma comum de sofrimento; as importantes ("explosivas", segundo Dumit) implicações jurídicas e administrativas da definição do distúrbio, especialmente para efeitos de atribuição de compensações ou do reconhecimento de invalidez; a grande diversidade das terapias, incluindo um amplo leque de terapias convencionais e alternativas; a relação e proximidade entre os distúrbios, que tornam frequentes os erros de diagnóstico; o uso de tecnologias de imagem do cérebro como recurso para o diagnóstico, sem que através delas, porém, seja garantida a produção de provas que permitam pôr termo às controvérsias.

A demonstração da natureza biológica (e não mental ou psiquiátrica) de uma doença é considerada, em muitos destes casos, condição crucial para o reconhecimento do direito a tratamento facultado por sistemas públicos ou privados de prestação de cuidados. Essa demonstração tende a reforçar a posição dos que reivindicam o reconhecimento da doença, dado que tanto os especialistas como os tribunais e instituições de saúde tendem a preferir os diagnósticos baseados em provas "duras" ou "objectivas". Essa prova, contudo, serve apenas para demonstrar a existência de dano biológico, não a sua causa ou etiologia. Nos Estados Unidos, apesar dos riscos de diagnóstico errado ligado a limitações de tecnologias disponíveis, como o PET (Tomografia por Emissão de Positrões), os doentes preferem correr esse risco a serem "excluídos do diagnóstico", o que os deixaria sem acesso a cuidados (Dumit, 2000: 221). São ainda limitados os estudos sociológicos e antropológicos realizados fora dos Estados Unidos sobre estes distúrbios e sobre os que por eles são afectados. A abordagem comparativa permitiria, certamente, identificar as diferentes configurações de relações entre os saberes e tecnologias biomédicos, os saberes baseados na experiência dos afectados, os processos de objectivação do distúrbio como doença e os usos desses saberes em contextos judiciais, administrativos e políticos. Aspectos centrais para essa abordagem comparativa seriam, ainda, as diferenças na definição do distúrbio e dos meios mobilizados para o seu diagnóstico, no acesso a cuidados de saúde e nas formas de mobilização colectiva e de biossocialidade.

Um segundo tipo frequente de controvérsia e de mobilização ocorre em relação a doenças associadas ao ambiente - incluindo o ambiente laboral - ou a doenças que afectam - ou que afectam desproporcionadamente - as mulheres, e por isso levam ao envolvimento de movimentos pela saúde ambiental ou pela justiça ambiental e de movimentos ou organizações que 
lutam pela saúde das mulheres. É frequente a convergência entre estes diferentes tipos de movimentos, dado que muitos dos problemas de saúde que afectam as mulheres têm origem, precisamente, em contaminações ou agressões ambientais (Brown, 2007; Allen, 2003; Corburn, 2005). O que está em jogo nestes casos não é a existência de uma dada doença, mas o reconhecimento da relação entre uma doença e um certo tipo de actividade ou de exposição (por exemplo, contaminação por tóxicos), mesmo que ela não possa ser provada pelo modelo epidemiológico dominante ou por modelos explicativos correntes na biomedicina. Aquilo que se procura estabelecer é o nexo causal entre uma exposição e os seus efeitos e a etiologia da doença. A doença pode ser conhecida, mas pode ser negada pelos especialistas ou por outros actores (Estado ou indústria, por exemplo) a associação entre as manifestações da doença e a exposição a um agente contaminante (radiações, substâncias químicas, agentes biológicos), especialmente quando essa exposição ocorre em doses ou concentrações baixas, quando existe distância espacial entre o lugar de origem da contaminação e o lugar da exposição, quando existe um desfasamento temporal ou geracional entre a exposição e a manifestação de efeitos, ou ainda quando outros potenciais agentes contaminantes estão presentes. Os desenvolvimentos recentes, por um lado, da epigenética e da biologia ecológica do desenvolvimento (Gilbert e Epel, 2009) e, por outro, de abordagens ecossistémicas e ecossociais da saúde e da doença (Lewontin e Levins, 2007; Freitas e Porto, 2006; Porto, 2007; Matias, 2009) têm vindo a trazer importantes recursos científicos para a revisão dos conceitos de causa e de etiologia neste domínio.

Um outro aspecto a sublinhar é a importância de formas de investigação colaborativa entre populações ou grupos afectados, muitas vezes organizados em movimentos ou associações, e especialistas em saúde. Uma das formas mais eficazes que assume essa colaboração é o que Phil Brown (Brown e Mikkelsen, 1990; Brown, 2007) designou por epidemiologia popular, que permite responder às limitações que a epidemiologia convencional apresenta. $\mathrm{O}$ reconhecimento de um nexo causal entre uma exposição e um efeito, mesmo quando existe distância espacial e temporal entre um e outro, ou quando a sua relação envolve gerações diferentes (como acontece com exposições de mulheres grávidas a agentes contaminantes ou poluentes, que terão efeitos nos seus filhos), permite às populações e grupos afectados exigir o reconhecimento do dano biológico e promover acções no sentido da eliminação da fonte de contaminação ou de poluição, nomeadamente através de políticas públicas de protecção ou de remediação do ambiente. Graças a este tipo de iniciativas e à forma como elas tornaram possível a colaboração entre cientistas e grupos ou populações afectadas, tornou-se 
também possível demonstrar a acção danosa de substâncias resultantes da actividade industrial (como os disruptores endócrinos), renovar as visões sobre a carcinogénese, recuperando e relançando a reflexão e investigação sobre as causas ambientais do cancro ou promover políticas ambientais associadas à prevenção de doenças como a asma (Proctor, 1995; Sonnenschein e Soto, 1998; Krimsky, 2000; Colborn et al., 1996). As lutas pelo reconhecimento dos direitos de vítimas de acidentes industriais ampliados (Porto, 2007, Fortun, 2001; Centemeri, 2006) aparecem como outra importante faceta deste tipo de mobilizações.

$\mathrm{O}$ que têm em comum as formas de acção que foram tratadas nesta secção? $\mathrm{O}$ aspecto mais relevante parece ser o de elas porem em evidência uma relação entre a mobilização de concepções amplas de saúde e o facto de estas serem usadas para responder a situações em que existe já um dano identificável na saúde de pessoas, de populações, de grupos ou colectivos específicos e de ecossistemas. O resultado, em muitos casos, é a emergência de uma "experiência colectiva e politizada da doença" (Brown, 2007: 127).

No contexto do capitalismo neoliberal e dos sistemas de saúde "realmente existentes" na maior parte dos países do mundo, é visível uma assimetria marcada entre a capacidade de "realizar" a doença enquanto demonstração de um dano que obriga ao reconhecimento do direito a assistência e a compensação, mas também da necessidade de adoptar medidas para remediar e prevenir novos danos, e a capacidade de "realizar" medidas que assentam em acções positivas de promoção de um ambiente e de modos de vida saudáveis, nomeadamente através de intervenções sobre as principais causas de poluição, contaminação e destruição ambiental, e em particular sobre os modelos existentes de organização da produção e do consumo. As concepções "ampliadas" de saúde podem, nestas circunstâncias, ser mobilizadas para demonstrar relações causais e etiologias e para conferir credibilidade e legitimidade científica às reivindicações de reconhecimento da existência de doença e de dano biológico. O caminho para a saúde como direito parece, assim, passar, em muitos casos, no quadro actual de individualização somática e promoção da responsabilidade individual e da prevenção, pela luta pelo "direito à doença" e pela justiça sanitária. ${ }^{14}$

\footnotetext{
${ }^{14}$ Não abordo, neste artigo, as acções que visam a realização do direito à saúde através, por exemplo, da exigência de participação na definição de orientações e prioridades para as políticas de saúde ou para políticas públicas com implicações para a saúde, como, por exemplo, as políticas de ambiente, de trabalho ou de protecção do consumidor. Também não foi possível abordar, a não ser através de breves alusões, o fenómeno dos movimentos sociais ligados à saúde e das associações de doentes, que cobre um terreno muito vasto, que vai da luta pela medicalização e pelo "direito à doença" até aos movimentos pela desmedicalização (do parto ou de certas formas de deficiência, por exemplo). Sobre estes temas, veja-se Epstein (2008); Akrich et al. (2008).
} 


\section{Conclusão}

Uma comparação entre as dinâmicas do imperativo da saúde e da justiça sanitária poderia levar a concluir que a definição "positiva" da saúde como bem-estar geral teria tido como efeito a promoção da saúde centrada na responsabilização individual, enquanto muitos continuariam a lutar pelo reconhecimento da doença, numa aparente adesão à ideia de que a saúde tem a ver, sobretudo, com o tratar de doenças, e especialmente de doenças por cujo aparecimento os indivíduos não podem ser responsabilizados. O quadro, porém, está longe de ser tão simples. Cada uma dessas duas dinâmicas apresenta uma considerável heterogeneidade, dando lugar a configurações de saberes sobre a saúde e a formas de biopoder e de biossocialidade distintas, que redistribuem a responsabilidade e a capacidade de agir.

Os tipos de situações associadas à luta pela justiça sanitária configuram formas de biossocialidade distintas das que são constitutivas da saúde como imperativo. Se a partilha de características biológicas, ou de danos que afectam a biologia, é uma característica comum aos vários tipos de situações mencionadas, ela toma forma em configurações diferentes. Nuns casos, essa partilha passa pela objectivação realizada pelas práticas clínicas ou pela epidemiologia. São estas que permitem identificar um caso como pertencendo a uma dada classe, e, dessa forma, nomear a doença ou o problema. Noutros casos, são os próprios postulantes à condição de pessoas afectadas por problemas de saúde que se organizam colectivamente - e estabelecendo, frequentemente, alianças com cientistas e especialistas e com instituições de saúde e de investigação - para "dar a ver" essa condição, como ponto de entrada para a luta por "ter doenças" que o Estado e as instituições e profissionais de saúde não reconhecem ou cuja existência desconhecem ou ignoram. Em todas essas situações, contudo, o reconhecimento da condição de pessoa afectada - ou de grupo ou colectivo afectado - na sua saúde por agentes ou exposições ambientais ou por condições de vida, de habitação ou de trabalho aparece como um ponto de passagem obrigatório para o acesso a serviços e cuidados de saúde. É nesse sentido que se pode sugerir que a realização da saúde como direito passa pela luta por situações em que a saúde é posta em risco ou em que esse direito é violado. A objectivação e partilha da experiência dessas violações ganha forma através das formas de acção colectiva que visam a realização - parcial e situada - da justiça sanitária.

Mas é importante também sublinhar que, mesmo quando estamos a lidar com concepções "ampliadas" de saúde que não a reduzem à ausência de doença, e de intervenções na saúde que vão para além do "modelo biomédico”, continua a ser central para a realização da saúde como direito o acesso 
aos dispositivos de diagnóstico e terapêuticos da biomedicina. A própria biomedicina, contudo, começa a encontrar novos desafios associados, precisamente, aos novos "distúrbios sociomédicos" e às dificuldades de conhecimento da sua etiologia a partir dos modelos de causalidade inspirados no conhecimento das doenças infecciosas. A realização do direito à saúde aparece, pois, como um desafio tanto para a concepção "naturalista" de doença e de saúde proposta pela biomedicina como para as concepções ampliadas de saúde centradas no processo saúde-doença. O caminho mais produtivo para a resposta a esse desafio poderá passar por uma exploração mais intensa e precisa do processo de co-produção ou construção heterogénea da saúde como conhecimento, como experiência, como acção colectiva e como direito, das ontologias e epistemologias associadas a diferentes práticas e das políticas ontológicas que estas configuram. Este é, assumidamente, um programa ambicioso que aqui se pretendeu, apenas, esboçar.

\section{Referências bibliográficas}

Akrich, Madeleine et al. (orgs.) (2008), The Dynamics of Patient Organizations in Europe.

Paris: Presses de l'École des Mines.

Allen, Barbara L. (2003), Uneasy Alchemy: Citizens and Experts in Louisiana's Chemical Corridor Disputes. Cambrige, Massachusetts: MIT Press.

Almeida Filho, Naomar de (2000), A ciência da saúde. São Paulo: HUCITEC.

Baszanger, Isabelle (1995), Douleur et médecine, la fin d'un oubli. Paris: Seuil.

Berg, Marc; Mol, Annemarie (1998), Differences in Medicine: Unraveling Practices, Techniques, and Bodies. Durham, North Carolina: Duke University Press.

Biehl, João (2007), Will to Live: AIDS Therapies and the Politics of Survival. Princeton:

Princeton University Press.

Blaser, Mario (2009), "Political Ontology: Cultural Studies without 'Cultures'?", Cultural Studies, 23(5): 873-96.

Briggs, Charles L.; Mantini-Briggs, Clara (2003), Stories in the Time of Cholera: Racial Profiling during a Medical Nightmare. Berkeley: University of California Press.

Brown, Phil (2007), Toxic Exposures: Contested Illnesses and the Environmental Health Movement. New York: Columbia University Press.

Brown, Phil; Mikkelsen, Edwin J. (1997), No Safe Place: Toxic Waste, Leukemia, and Community Action. Berkeley: University of California Press [2 $2^{\mathrm{a}}$ edição revista].

Callon, Michel; Rabeharisoa; Vololona (2004), "Gino's Lesson on Humanity: Genetics, Mutual Entanglements and the Sociologist's Role", Economy and Society, 33(1): $1-27$.

Callon, Michel, et al. (2001), Agir dans un monde incertain. Essai sur la démocratie technique. Paris: Seuil. 
Campos, Gastão Wagner de Sousa et al. (orgs.) (2007), Tratado de saúde coletiva. São Paulo/Rio de Janeiro: Editora HUCITEC/Editora FIOCRUZ.

Carvalho, Sérgio Resende (2005), Saúde coletiva e promoção da saúde: sujeito e mudança. São Paulo: HUCITEC.

Castiel, Luís David; Alvarez-Dardet Diaz, Carlos (2007), A saúde persecutória: os limites da responsabilidade. Rio de Janeiro: Editora FIOCRUZ.

Centemeri, Laura (2006), Ritorno a Seveso. Il danno ambientale, il suo riconoscimiento, la sua riparazione. Milano: Bruno Mondadori.

Clarke, Adele E. et al. (2003), "Biomedicalization: Technoscientific Transformations of Health, Illness, and U.S. Biomedicine”, American Sociological Review, 68: 161-94.

Colburn, Theo et al. (1996), Our Stolen Future. New York: Dutton.

Coppel, Anne (2002), Peut-on civiliser les drogues? De la guerre à la drogue à la réduction des risques. Paris: La Découverte.

Corburn, Jason (2005), Street Science: Community Knowledge and Environmental Health Justice. Cambridge, Massachusetts: MIT Press.

Czeresnia, Dina (2003), "O conceito de saúde e a diferença entre prevenção e promoção”, in Czeresnia e Freitas (orgs.), 39-53.

Czeresnia, Dina; Freitas, Carlos Machado de (orgs.) (2003), Promoção da saúde: conceitos, reflexões, tendências. Rio de Janeiro: Editora FIOCRUZ.

Dumit, Joseph (2000), "When Explanations Rest: 'Good Enough' Brain Science and the New Sociomedical Disorders”, in Margaret Lock et al. (orgs.), Living and Working with the New Medical Technologies: Intersections of Inquiry. Cambridge: Cambridge University Press.

Dumit, Joseph (2006), "Illnesses You Have to Fight to Get: Facts as Forces in Uncertain, Emergent Illnesses”, Social Science E Medicine, 62(3): 577-90.

Epstein, Steven (2007), Inclusion: The Politics of Difference in Medical Research. Chicago: University of Chicago Press.

Epstein, Steven (2008), "Patient Groups and Health Movements", in Edward J. Hackett et al. (orgs.), The Handbook of Science and Technology Studies. Third Edition. Cambridge, Massachusettts: MIT Press, 499-539.

Escobar, Arturo (2007), "Worlds and Knowledges Otherwise”, Cultural Studies, 21(2): 179-210.

Farmer, Paul (2005), Pathologies of Power: Health, Human Rights, and the New War on the Poor. Berkeley: University of California Press.

Fortun, Kim (2001), Advocacy after Bhopal: Environmentalism, Disaster, New Global Orders. Chicago: University of Chicago Press.

Fassin, Didier (2004), "Social Illegitimacy as a Foundation of Health Inequality: How the Political Treatment of Immigrants Illuminates a French Paradox", in Arachu Castro; Merrill Singer (orgs.), Unhealtby Health Policy: A Critical Anthropological Examination. Walnut Creek: Altamira Press, 203-214. 
Foucault, Michel (2004), Naissance de la biopolitique. Paris: Gallimard/Seuil.

Freitas, Carlos Machado; Porto, Marcelo Firpo (2006), Saúde, ambiente e sustentabilidade. Rio de Janeiro: Editora FIOCRUZ.

Gibbon, Sahra; Novas, Carlos (orgs.) (2008), Biosocialities, Genetics and the Social Sciences: Making Biologies and Identities. London: Routledge.

Gilbert, Scott F.; Epel, David (2009), Ecological Developmental Biology: Integrating Epigenetics, Medicine, and Evolution. Sunderland, Massachusetts: Sinauer Associates Inc.

Illich, Ivan (1978), Némesis Médica. México D.F.: Editorial Joaquín Mortiz SA.

Jasanoff, Sheila (org.) (2004), States of Knowledge: The Co-Production of Science and Social Order. London: Routledge.

Klawiter, Maren (2002), "Risk, Prevention and the Breast Cancer Continuum: The NCI, the FDA, Health Activism and the Pharmaceutical Industry", History and Technology, 18(4): 309-353.

Krimsky, Sheldon (2000), Hormonal Chaos: The Scientific and Social origins of the Environmental Endocrine Hypothesis. Baltimore: Johns Hopkins University Press.

Kroll-Smith, Steve; Floyd, H. Hugh (1997), Bodies in Protest: Environmental Illness and the Struggle over Medical Knowledge. New York: New York University Press.

Lakoff, Andrew (2008), “The Right Patients for the Drug: Pharmaceutical Circuits and the Codification of Illness", in Edward J. Hackett et al. (orgs.), The Handbook of Science and Technology Studies. Third Edition. Cambridge, Massachusettts: MIT Press, 741-59.

Latour, Bruno (1987), Science in Action: How to Follow Scientists and Engineers through Society. Milton Keynes: Open University Press.

Lewontin, Richard; Levins, Richard (2007), Biology under the Influence: Dialectical Essays on Ecology, Agriculture, and Health. New York: Monthly Review Press.

Lupton, Deborah (1995), The Imperative of Health: Public Health and the Regulated Body. Thousand Oaks: Sage.

Matias, Marisa (2009) A natureza farta de nós? Coimbra: Faculdade de Economia da Universidade de Coimbra (tese de Doutoramento).

Meneses, Maria Paula G. (2004), "Quando não há problemas, estamos de boa saúde, sem azar nem nada': para uma concepção emancipatória da saúde e das medicinas”, in Santos (org.), 357-91.

Mol, Annemarie (2002), The Body Multiple: Ontology in Medical Practice. Durham, North Carolina: Duke University Press.

Mol, Annemarie (2008), The Logic of Care: Health and the Problem of Choice. London: Routledge.

Murphy, Michelle (2006), Sick Building Syndrome and the Problem of Uncertainty: Environmental Politics, Technoscience, and Women Workers. Durham, North Carolina: Duke University Press. 
Nathan, Tobie (2001), Nous ne sommes pas seuls au monde. Paris: Les Empêcheurs de penser en rond.

Nathan, Tobie (2007), À qui j’appartiens? Écrits sur la psychothérapie, sur la guerre et sur la paix. Paris: Les Empêcheurs de penser en rond.

Nathan, Tobie; Stengers, Isabelle (1995), Médecins et sorciers. Paris: Les Empêcheurs de penser en rond.

Neto, Eleutério Rodriguez (2003), Saúde: promessas e limites da constituição. Rio de Janeiro: Editora FIOCRUZ.

Novas, Carlos; Rose, Nikolas (2000), "Genetic Risk and the Birth of the Somatic Individual”, Economy and Society, 29(4): 485-513.

Nunes, João Arriscado (2008), “A retomada político-emancipatória em tempos de globalização: a saúde como laboratório”, Tempus - Actas de Saúde Coletiva, 2(1): 87-102.

Nunes, João Arriscado (2009), “O resgate da epistemologia”, in Santos; Meneses (orgs.), 215-242.

Oitava Conferência Nacional de Saúde (1986), Relatório Final (mimeo).

Peretti-Watel, Patrick; Moati, Jean-Paul (2009), Le principe de prévention: Le culte de la santé et ses dérives. Paris: Seuil.

Petryna, Adriana (2002), Life Exposed: Biological Citizens after Chernobyl. Princeton: Princeton University Press.

Petryna, Adriana (2009), When Experiments Travel: Clinical Trials and the Global Search for Human Subjects. Princeton: Princeton University Press.

Pignarre, Philippe (2001), Comment la dépression est devenue une épidémie. Paris: La Découverte.

Porto, Marcelo Firpo de Souza (2007), Uma ecologia política dos riscos. Rio de Janeiro: Editora FIOCRUZ.

Proctor, Robert N. (1995), Cancer Wars: How Politics Shapes What We Know and Don't Know About Cancer. New York: Basic Books.

Rabinow, Paul (1996), "Artificiality and Enlightenment: From Sociobiology to Biosociality", in Essays on the Anthropology of Reason. Princeton: Princeton University Press, 91-111.

Rabinow, Paul; Rose, Nikolas (2003), “Thoughts on the Concept of Biopower Today”. Disponível em: http://www2.lse.ac.uk/sociology/pdf/RabinowandRose-BiopowerToday03.pdf (acedido em 12.01.2009).

Rose, Nikolas (2007), The Politics of Life Itself: Biomedicine, Power, and Subjectivity in the Twenty-First Century. Princeton: Princeton University Press.

Santos, Boaventura de Sousa (2009), "Para além do pensamento abissal: das linhas globais a uma ecologia de saberes", in Santos; Meneses (orgs.), 23-71.

Santos, Boaventura de Sousa (org.) (2004), Semear outras soluções. Os caminhos da biodiversidade e dos conhecimentos rivais. Porto: Afrontamento. 
Santos, Boaventura de Sousa; Meneses, Maria Paula (orgs.) (2009), Epistemologias do Sul. Coimbra: Almedina.

Sen, Amartya (2009), The Idea of Justice. Cambridge, Massachusetts: Harvard University Press.

Sfez, Lucien (1995), La santé parfaite. Paris: Seuil.

Sonnenschein, Carlos; Soto, Ana M. (1998), The Society of Cells: Cancer and Control of Cell Proliferation. New York: Springer Verlag.

Szasz, Thomas (2007), The Medicalization of Everyday Life: Selected Essays. Syracuse, New York: Syracuse University Press.

Szasz, Andrew (2008), Shopping our Way to Safety: How We Changed from Protecting the Environment to Protecting Ourselves. Minneapolis: University of Minnesota Press.

Taylor, Peter J. (2005), Unruly Complexity: Ecology, Interpretation, Engagement. Chicago: University of Chicago Press.

Young, Allan (1995), The Harmony of Illusions: Inventing Post-Traumatic Stress Disorder. Princeton: Princeton University Press. 